\title{
Ableism: the undiagnosed malady afflicting medicine
}

\author{
Cite as: CMAJ 2019 April 29;191:E478-9. doi: 10.1503/cmaj.180903
}

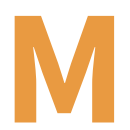

edicine has traditionally been viewed as a benevolent discipline in which every human life is valued equally, without any form of prejudice or discrimination. Although this may remain the ideal to which medicine aspires, the reality is that, as individuals, medical professionals are not immune to the influence of dominant societal understandings of, and attitudes toward, individuals and groups of people deemed to be "others."

Galli and colleagues observe that "[d]espite their intentions, personal goals and normative expectations, even health professionals are unconscious bearers of implicit social biases that affect the quality of professional interventions." ${ }^{1}$ They further contend that "[i]mmediately, and from early life and thereafter, people perceive individuals with disability as 'vulnerable' and of low competence, and, accordingly, treat members of this group differently." ${ }^{1}$ Consequently, people with disabilities often continue to experience social devaluation on account of their disabilities (i.e., ableism), despite the fact that the last few decades have seen an increased awareness and a decreased social acceptability of discrimination based on other characteristics such as race (i.e., racism) and gender (i.e., sexism). People with disabilities thus remain subjected to ableist attitudes in many sectors, including - often especially the health care system. ${ }^{2}$

Disability scholar Fiona Kumari Campbell defines ableism as "a network of beliefs, processes and practices that produces a particular kind of self and body (the corporeal standard) that is projected as the perfect, species-typical and

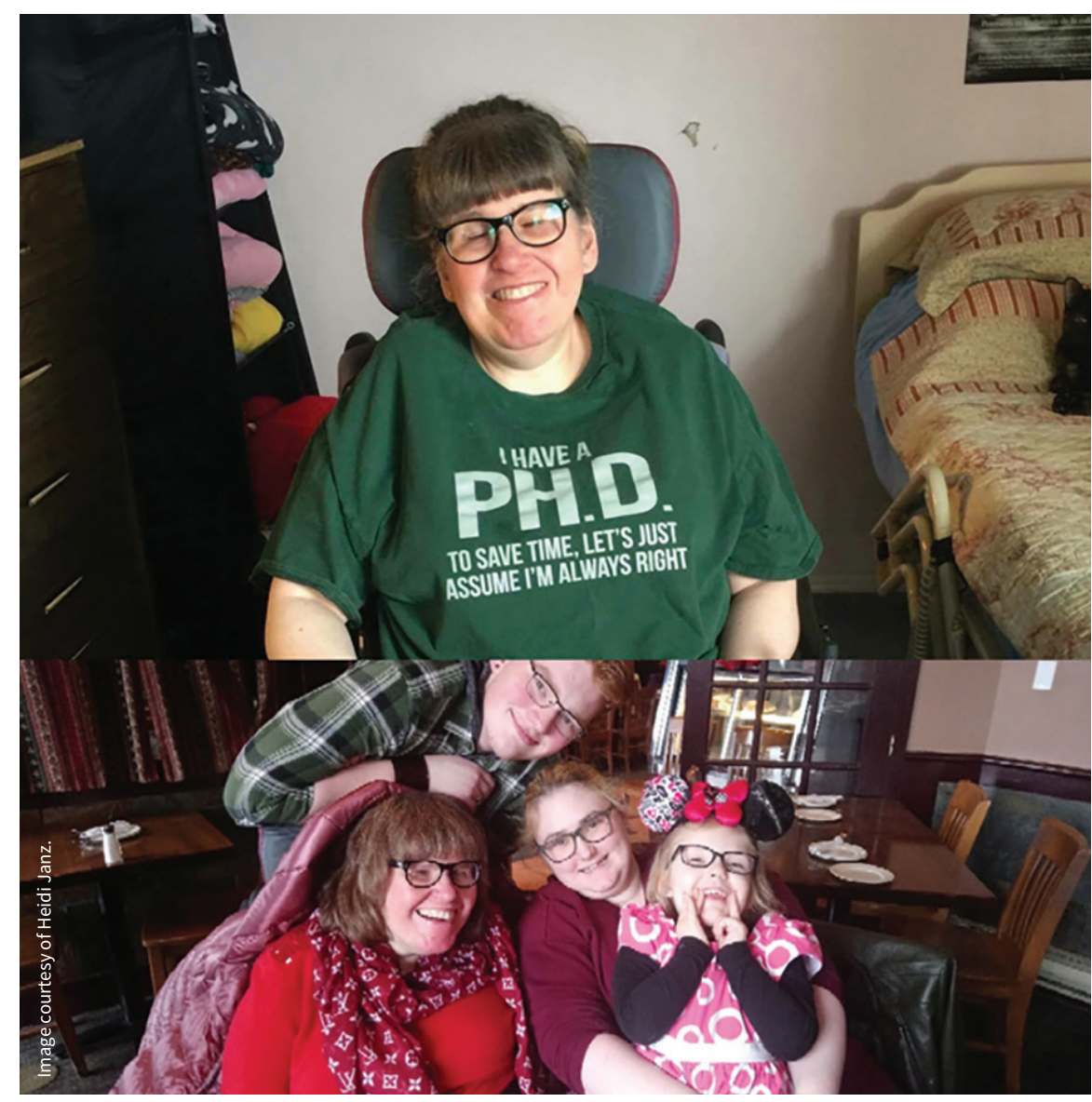

The author, Heidi Janz, is a specialist in disability ethics, a writer and a playwright.

therefore essential and fully human. Disability then, is cast as a diminished state of being human." ${ }^{3}$ Campbell delineates an inherent link between this deficit-based construction of disability and a "biomedicalist stance," which, since the Age of Reason, has "played a critical intervening role in the lives of people with disability and people with anomalous bodies or mentalities. Medicine has operated as the primary paradigm not only for the treat- ment of disabled bodies but has also shaped the way decision makers, legislators, families and society in general think about and sense disability." 4

It is, therefore, both serious and troubling that studies have consistently shown that, as a group, health care professionals tend to underestimate substantially the quality of life of people with disabilities. ${ }^{5}$ Indeed, the very notion of "quality of life" as a reliable indicator of 
the appropriateness or inappropriateness of a medical course of treatment for a person with disabilities is thus deeply problematic. Jeffrey Martin observes that "a major conundrum when doing health related quality of life [HRQL] research is that most measures, including a very popular one (i.e., the SF-36) confound health and function. As a result researchers can erroneously suggest that particular groups (e.g., disability versus nondisability samples) differ in HRQL when they really differ in function." Such erroneous judgments about the quality of life experienced by people with disabilities can result in treatment options for people with disabilities being either limited, or altogether eliminated. ${ }^{7}$ At the heart of such decisions is what disability scholar Joel Reynolds has termed the "ableist conflation" of disability, suffering and death: "wherever operative, the ableist conflation flattens communication about disability to communication about pain, suffering, hardship, disadvantage, morbidity, and mortality." disabilities entering the medical realm is that things that are considered routine parts of daily living within the disability community, such as the use of feedingtubes and respirators, suddenly become indicators of an unacceptably low quality of life.

What, then, is the best practice for treating medical ableism, given its longstanding entrenchment in medicine and health care? Many disability and disability ethics scholars advocate for the introduction and increased inclusion of the perspectives of people with disabilities into medical and bioethical curricula as a means of combatting medical ableism. Joseph Stramondo argues that "the social identity of disability can structure personal experience so that an individual more easily perceives and reasons about the morally salient features of a situation in which one is trying to protect a disabled person's autonomy in a context of ableist structural oppression." ${ }^{11}$ Thus, exposing medical and bioethics students to the lived experiences of people with

\section{What makes medical ableism so dangerous and so insidious is that it often presents as "common sense."}

What makes medical ableism so dangerous and so insidious is that it often presents as "common sense." James Cherney argues that "ableism is that most insidious form of rhetoric that has become reified and so widely accepted as common sense that it denies its own rhetoricity - it 'goes without saying." "9 Within this milieu of "common sense" ableism, people with disabilities are routinely made vulnerable in medical settings. This is because "common sense" ableism in medicine very often results in the application of a utilitarian approach to defining "extraordinary," "heroic" and "futile" measures that may be employed to preserve or prolong human life. ${ }^{10}$ The danger that this poses for people with disabilities would create opportunities for them to, in the words of Tanya Titchkosky, "reconsider the place and meaning of abnormalcy as an opening on the meaning of normalcy." 12 Consequently, as Tom Shakespeare contends, "undoubtedly, an immersion in the personal testimonies of disabled people and in the empirical evidence of their lives would challenge dominant tragedy tropes and hugely improve the understanding of nondisabled bioethicists." ${ }^{13}$

I would extend this argument to include not just bioethicists, but all health care practitioners. Only if and when health care providers, educators and students are routinely and meaningfully exposed to the perspectives of people with disabilities can they develop a consistent proficiency in diagnosing and treating ableism, in their profession generally as well as in their own practice. Only through such a process of transformative education leading to systemic change can health care in Canada be rehabilitated into a safe space for people with disabilities.

\section{Heidi L. Janz PhD}

John Dossetor Health Ethics Centre, University of Alberta, Edmonton, Alta.

\section{References}

1. Galli G, Lenggenhager B, Scivoletto G et al. 'Don't look at my wheelchair!' The plasticity of longlasting prejudice. Med Educ 2015;49:1239-47.

2. Du Mont J, Forte T. Perceived discrimination and self-rated health in Canada: an exploratory study. BMC Public Health 2016;16:742-52.

3. Campbell FK. Inciting legal fictions: disability's date with ontology and the ableist body of the law. Griffith Law Rev 2001;10:42-62.

4. Campbell FK. Medical education and disability studies. J Med Humanit 2009;30:221-35.

5. Kothari S, Kirschner KL. Abandoning the golden rule: the problem with "putting ourselves in the patient's place." Top Stroke Rehabil 2006;13: 68-73.

6. Martin JJ. People with disabilities and quality of life: the role of physical activity. In: Mitchell L, editor. Physical disabilities: perspectives, risk factors, and quality of Life. New York: Nova Science Publishers;2017:1-15.

7. Stienstra D, Chochinov HM. Palliative care for vulnerable populations. Palliat Support Care 2012;10:37-42.

8. Reynolds JM. "I'd rather be dead than disabled" - the ableist conflation and the meanings of disability. Rev Comm 2017;17:149-63.

9. Cherney JL. The rhetoric of ableism. Disabil Studies Quar 2011;31:3. Available: http://dsq-sds.org/ article/view/1665/1606 (accessed 2018 Oct. 17).

10. Hansen N, Janz H. The ethics of making space for non-conformist bodies and minds in healthcare. Dev Disabil Bull 2009;37:29-43.

11. Stramondo JA. Why bioethics needs a disability moral psychology. Hastings Cent Rep 2016;46: 22-30.

12. Titchkosky T. Life with dead metaphors. JLCDS 2015;9:1-16.

13. Shakespeare T. Just what is the disability perspective on disability? Hastings Cent Rep 2016; 46:31-2.

This article has been peer reviewed.

Editor's note: A National Film Board of Canada documentary on the author is available at www.nfb.ca/film/we_regret_to_inform_you. 